\title{
Effects of routine care procedures on transcutaneous oxygen in neonates: a quantitative approach
}

\author{
DAVID A DANFORD, STEPHANIE MISKE, JOHN HEADLEY, AND ROBERT M NELSON
}

Department of Pediatrics, Division of Neonatology, University of Nebraska Medical Center, Omaha, Nebraska, USA

SUMMARY The changes in transcutaneous oxygen tension $\left(\mathrm{TcPo}_{2}\right)$ during 123 observations of 10 care procedures were compared with the intrinsic variability of the $\mathrm{TcPo}_{2}$ at the time of the procedures. Standard deviations of the $\mathrm{TcPo}_{2}$ were measured by planimetry from continuous recording in $\overrightarrow{\tilde{N}}$ undisturbed infants during a 10-minute control period immediately before each procedure. The decrement of $\mathrm{TcPO}_{2}$ during the procedure and the change in $\mathrm{TcPO}_{2} 5$ minutes after the procedure had $\stackrel{?}{工}$ ended were measured. A chest $x$-ray film had the most striking early hypoxic effect, but all the $\vec{c}$ procedures produced early hypoxia in at least one-quarter of the infants. The significant decreases in $\stackrel{\varrho}{=}$ oxygenation with particular procedures indicate areas in which changes in techniques might be applied to the benefit of the neonate.

The tenuous respiratory status of many preterm infants in the neonatal intensive care unit places them at high risk from the potential stresses of routine care procedures. Since it is largely unknown which procedures most compromise such infants it is important to establish and quantitate the risks so that the hazards of life in the intensive care unit can be minimised.

The development of transcutaneous oxygen tension $\left(\mathrm{TcPO}_{2}\right)$ measurement techniques ${ }^{1-3}$ provides a tool with which oxygenation may be continuously and non-invasively monitored during routine care procedures. Other investigators have reported drops in $\mathrm{TcPO}_{2}$ during feeding, tracheal suctioning, ${ }^{45}$ apnoeic episodes, ${ }^{6-8}$ change in behavioural state, ${ }^{6910}$ and circumcision. ${ }^{11}$ While absolute changes in $\mathrm{TcPo}_{2}$ have been measured in some procedures, little work attempting to compare these changes with the baseline $\mathrm{TcPo}_{2}$ variability has been published. ${ }^{12}$ By relating the maximal fall in $\mathrm{TcPo}_{2}$ during each of 10 routine care procedures to the intrinsic variability of $\mathrm{TcPO}_{2}$ in the resting state, this investigation has established the magnitude of hypoxia to which each procedure subjects neonates.

\section{Materials and methods}

Altogether 123 recordings of $\mathrm{TcPo}_{2}$ were made on 36 infants ranging in chronological age from 1 to 78 days and in gestational age from 24 to 38 weeks. Most had some degree of respiratory disease, either respiratory distress syndrome or bronchopulmonary dysplasia. Infants were excluded if they had congenital heart disease, anaemia (haematocrit $<30 \%$ ), hypotension (systolic blood pressure $<30 \mathrm{mmHg}$ ), or severe skin disease. Infants were chosen if they $\stackrel{\unrhd}{\complement}$ needed chest $x$-ray films, blood taken by heel prick, $\overrightarrow{\vec{D}}$ bottle feeding, tube feeding, weighing, chest physio- 3 therapy with suction, or temperature and heart rate $\vec{F}$ measurement. Other normal infants were chosen for recording during elective changing of napkins, application of $\mathrm{TcPO}_{2}$ monitor, and while switching on a phototherapy light (only those babies receiving $\dot{0}$ phototherapy) at a time when the infants' care was not interrupted by our recording.

A $\mathrm{TcPO}_{2}$ electrode (Radiometer TCM-1; the London Co., Cleveland Ohio) was applied to the 웅 infant's skin and allowed to warm up to $44^{\circ} \mathrm{C}$. As $>$ soon as the $\mathrm{TcPo}_{2}$ reading was stable (generally after about 10 minutes) a 10 -minute control period was recorded on a strip chart (Omni Scribe Recorder; $\sigma$ Houston Instruments; Austin, Texas) during which N the baby was not disturbed. Immediately after the $\mathrm{N}^{N}$ control, the procedure was performed and the 0 recording was continued. After the procedure ended the recording was continued for 5 minutes. If the electrode became detatched from the skin or if $\stackrel{0}{?}$ another procedure needed to be performed, the $T$ recording was stopped.

A planimetered mean $\mathrm{TcPo}_{2}$ was obtained during $\underset{\mathbb{D}}{\mathbb{D}}$ the control period of each recording. Assuming a $\vec{D}$ Gaussian distribution of variation from the mean $\frac{\Omega}{0}$ 


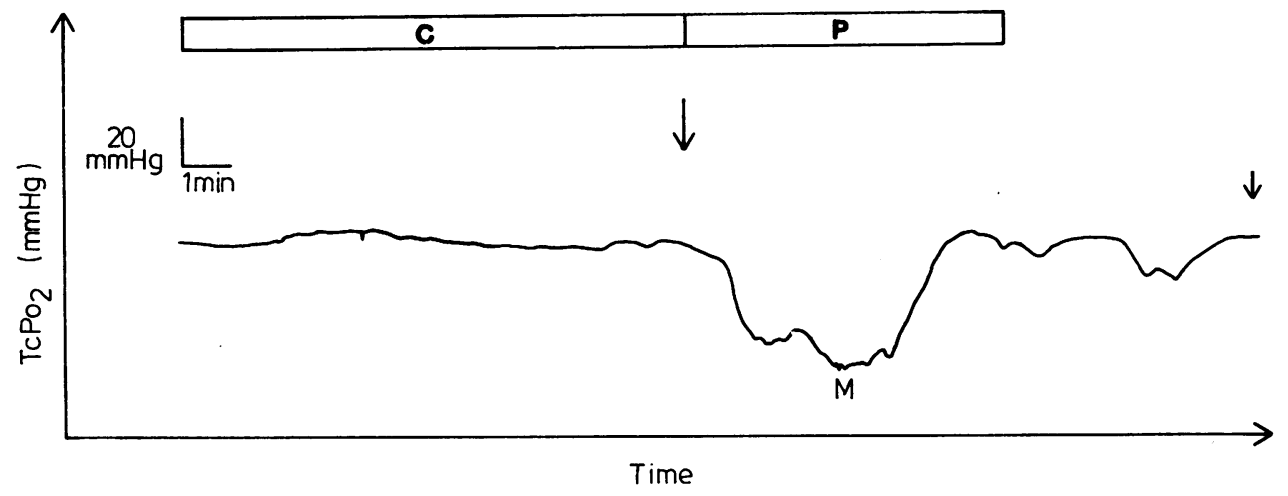

Fig. 1 A sample recording $\mathrm{TcPo}_{2}$ against time during a chest $x$-ray film in a neonate. $C$ indicates the 10-minute control period. $P$ is the duration of the procedure. The long arrow indicates the point at which the end control TcPo ${ }_{2}$ is measured while the short arrow shows the point at which the 5-minute post procedure $\mathrm{TcPo}_{2}$ is measured. M is the minimum $\mathrm{TcPo}_{2}$ during the procedure.

during the control period, a standard deviation (SD) of $\mathrm{TcPo}_{2}$ about the mean was obtained using the area above and below the mean enclosed by the curve. The end control $\mathrm{TcPo}_{2}$ was noted as were the minimum $\mathrm{TcPO}_{2}$ during the procedure and the $\mathrm{TcPO}_{2} 5$ minutes after the end of the procedure (Fig. 1).

An acute fall in $\mathrm{TcPo}_{2}$ was determined by subtracting the minimum $\mathrm{TcPO}_{2}$ during the procedure from the end control $\mathrm{TcPO}_{2}$ and dividing the result by $\mathrm{SD}$. The late change in the $\mathrm{TcPo}_{2}$ was determined by subtracting the $\mathrm{TcPo}_{2} 5$ minutes after the procedure from the end control $\mathrm{TcPO}_{2}$ and dividing by the SD. Acute falls of greater than 1.64 SD were reported as statistically significant at the 0.05 level (one tailed standard curve), and the proportion of babies undergoing each procedure with this magnitude of acute fall in $\mathrm{TcPO}_{2}$ was recorded. Late changes (rises or falls) in $\mathrm{TcPo}_{2}$ were reported as statistically significant at the 0.05 level if greater than 1.96 SD (two-tailed standard curve).

\section{Results}

Altogether 123 recordings of $\mathrm{TcPo}_{2}$ were made during routine intensive care procedures (Fig. 2). Every procedure resulted in a statistically significant immediate fall in $\mathrm{TcPO}_{2}$ in at least some of the babies. Chest $x$-ray films had the most frequent immediate effect, producing a fall in all of them. Immediate falls in $\mathrm{TcPO}_{2}$ were seen in most of the procedures tested $(40-70 \%$ of babies), while changing of napkins was associated with a fall in $29 \%$.

At 5 minutes after the disturbance, most procedures showed a nearly symmetrical distribution between rises and falls. Several exceptions are notable in which late rises in $\mathrm{TcPo}_{2}$ grossly outnumber falls. Two diagnostic tests (chest $x$-ray films and measurement of temperature and heart rate) and

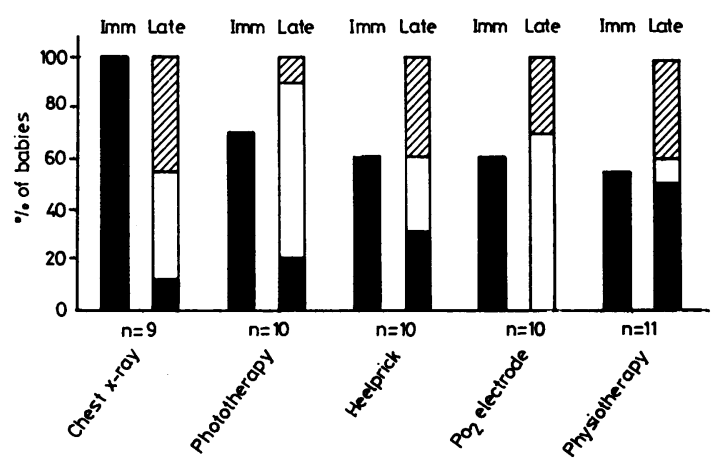

Significant $\left(0.05\right.$ level) fall in $\mathrm{TCPO}_{2}$ No significant change in $\mathrm{TcPO}_{2}$ Significant $(0.05$ level $)$ rise in $\mathrm{TcPO}_{2}$
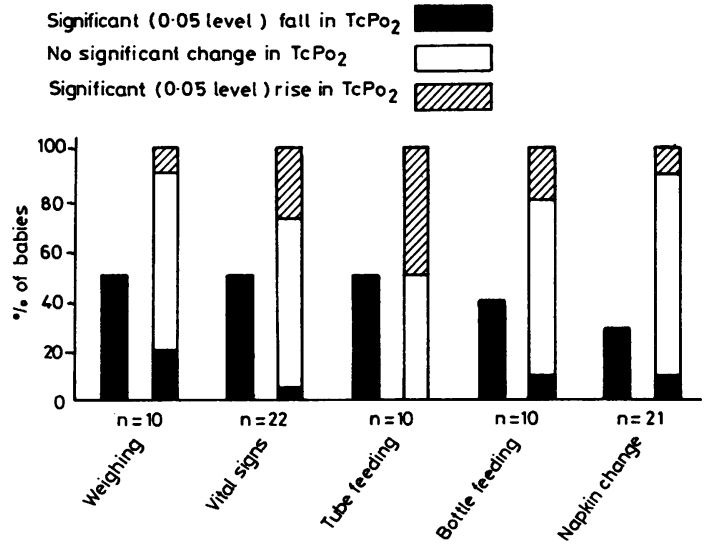

Fig. 2 Proportions of infants exhibiting immediate and late changes in $\mathrm{TcPo}_{2}$. 
two therapeutic interventions (pulmonary toilet and tube feeding) fit this category. None of the 10 procedures resulted in a substantial trend downwards in $\mathrm{TcPO}_{2}$ at 5 minutes.

The value of the SD varied from infant to infant, but in the mixed sample of intensive care patients SD averaged $6.7 \mathrm{mmHg}$ in the resting state. A significant immediate fall in $\mathrm{TcPo}_{2}$ therefore averaged $11 \mathrm{mmHg}$, and a significant rise or fall in the level 5 minutes after the procedure averaged $13 \mathrm{mmHg}$. No significant differences between groups could be established when SD was analysed by patient weight, gestational age, and chronological age.

\section{Discussion}

The results of this study are consistent with other work in this field. Hanson and Okken ${ }^{10}$ have recently studied the $\mathrm{TcPO}_{2}$ in infants during different behavioural states. They found significantly higher oxygen tension $\left(\mathrm{Po}_{2}\right)$ during quiet sleep than during active sleep; however during an alert active state and during crying the $\mathrm{Po}_{2}$ was also higher than during active sleep. Infants apparently undergo a constantly changing physiology of blood oxygenation based on behavioural state alone, so external influences could be profound in the magnitude of their effects. Indeed this was the case in the study of Rawlings et al.11 when they noted the points during the circumcision which were associated with pain were also the points during which the recorded $\mathrm{TcPO}_{2}$ was at its lowest. They could not demonstrate evidence of right-to-left shunting through the ductus arteriosus using simultaneous right upper quadrant and abdominal recordings; however this of course would not exclude intrapulmonary or intracardiac (patent foramen ovale) shunting. Agitation and crying associated with loud noises ${ }^{13}$ has also been correlated with a fall in $\mathrm{TcPo}_{2}$ and with increased intracranial pressure.

Rapid changes in $\mathrm{Po}_{2}$ to the point of hypoxia or hyperoxaemia have well-known adverse effects on infants. It is therefore advisable to minimise these changes as much as is permitted by the constraints of adequate patient care. The transcutaneous $\mathbf{P o}_{2}$ monitor allows much closer continuous observation of $\mathrm{PO}_{2}$ and has been applied with success to reduce 'undesirable time' ( $\mathrm{Po}_{2}$ too high or too low $) .^{14}$

Our data indicate that nearly all care-orientated stimulus commonly given to preterm infants in the intensive care unit can result in a fall in $\mathrm{TcPo}_{2}$. In general, the more intense the stimulus, the more dependable is the fall in $\mathrm{TcPo}_{2}$. The taking of a chest $x$-ray film, for example, involves several elements which theoretically may combine to produce hypoxia in our infants. Firstly, the raising of an infant's arms above the head and stretching the chest across an $x$-ray film cassette could have a significant restrictive effect. Secondly, this stimulation usually produces crying and struggling which may decrease the efficiency of breathing. Stimulus-induced crying with struggling would have to be regarded as physiologically different from spontaneous crying observed by Hanson and Okken ${ }^{10}$ to increase $\mathrm{Po}_{2}$. Finally, the cold stress of taking a chest $x$-ray film may alter pulmonary and systemic vascular tone such that intrapulmonary or interatrial right-to-left shunting might produce hypoxia.

Other procedures, seemingly less traumatic than a chest $x$-ray film, such as blood collection from heel prick, chest physiotherapy, weighing, and measurement of temperature and heart rate probably affect the $\mathrm{TcPo}_{2}$ through some of the same mechanisms. Minor stimulation of infants such as the placement of a $\mathrm{TcPO}_{2}$ transducer or initiating phototherapy produce transient hypoxia as frequently as some of the more blatantly intrusive procedures.

It is reassuring that none of the 10 commonly performed procedures produced a demonstrable trend towards hypoxia 5 minutes after completion. Some of the more vigorous procedures including chest $x$-ray film and chest physiotherapy were followed by a rise in $\mathrm{TcPO}_{2}$ more frequently than a fall. Care was taken to provide supplemental oxygen for several seconds after chest physiotherapy; however because of the transient nature of the supplementation, it is unlikely that this explains the favourable late trend. The beneficial effects of the procedure itself on pulmonary function are probably responsible. The arousal of the baby from active sleep to alertness which has been demonstrated to increase $\mathrm{TcPO}_{2}$ may cause the rise in $\mathrm{TcPo}_{2} \cdot{ }^{10}$ This effect may play a primary role in the rises observed after a chest $x$-ray film.

Feeding an infant, particularly by tube, results in a late trend upwards in $\mathrm{TcPo}_{2}$. Effects of vascular redistribution of blood flow to the gut upon oxygenation are uncertain but may play a role. It seems possible however, that the level of consciousness of a baby 5 minutes after feeding is more likely to lead to higher $\mathrm{TcPO}_{2}$ than immediately before feeding.

Evaluation of new methods for performing the procedures necessary for care of the sick newborn could apply the analysis techniques used in this paper to compare the degree of induced hypoxia and thus improve the care of the newborn infant. This would allow a standardised and quantified approach to such analysis.

We thank the nursing, respiratory therapy, and paediatric house staff for assistance. 


\section{References}

1 Huch R, Huch A, Lubbers D W. Transcutaneous measurement of blood pO2 (tcPO2)-method and application in perinatal medicine. J Perinat Med 1973; 1: 183-91.

2 Huch R, Lubbers D W, Huch A. Reliability of transcutaneous monitoring of arterial $\mathrm{pO} 2$ in newborn infants. Arch Dis Child 1974; 49: 213-8.

${ }^{3}$ Fenner A, Müller R, Busse H G, Junge M, Wolfsdorf J. Transcutaneous determination of arterial oxygen tension. Pediatrics 1975; 55: 224-31.

4 Huch R, Huch A, Albani M, et al. Transcutaneous pO2 monitoring in the routine management of infants and children with cardiorespiratory problems. Pediatrics 1976; 57: 681-90.

5 Leraillez J, Iannascoli F, Brioude R, Canet J. Cutaneous pO2: value of analysis of the tracings in neonatal cardiorespiratory pathology. Birth Defects $1979 ; 15$ : No 4, 399-406.

6 Friis-Hansen B, Lou H C, Marstrand-Christiansen P, Scheibel $\mathrm{E}$. The influence of apnea and physical activity on arterial blood pressure and transcutaneous oxygen tension in the newborn. Birth Defects 1979; 15: No 4, 461-8.

7 Monin P, Vert P, Andre M, Vibert M. Transcutaneous pO2 monitoring (tcPO2) in the newborn during apneic spells, convulsions, cardiac catheterizations, and exchange transfusions. Birth Defects 1979; 15: No 4, 469-91.
8 Peabody J L, Gregory G A, Willis M M, Philip A G, Lucey J F. Failure of conventional monitoring to detect apnea resulting in hypoxemia. Birth Defects 1979; 15: No 4, 274-84.

9 Martin R J, Okken A, Rubin D. Changes in arterial oxygen tension during active and quiet sleep in the neonate. Birth Defects $1979 ; 15$ : No 4, 493-4.

10 Hanson N, Okken A. Transcutaneous oxygen tension of newborn infants in different behavioral states. Pediatr Res 1980; 14: 911-5.

11 Rawlings D J, Miller P A, Engle R R. The effect of circumcision on transcutaneous PO2 in term infants. Am J Dis Child 1980; 134: 676-8.

12 Watts J L, Sinclair J C. Expression of continuous transcutaneous recordings of PO2. Acta Anaesthesiol Scand [Suppl] 1978; Supplement 68, 98-100.

13 Long J G, Lucey J F, Philip A G S. Noise and hypoxemia in the intensive care nursery. Pediatrics $1980 ; 65: 143-5$.

14 Long J G, Philip A G S, Lucey J F. Excessive handling as a cause of hypoxemia. Pediatrics $1980 ; 65: 203-7$.

Correspondence to Dr Robert $M$ Nelson, Jr, Department of Pediatrics, University of Nebraska Medical Center, 42nd and Dewey Avenue, Omaha, Nebraska 68105, USA.

Received 21 July 1982 